\title{
Entransy-dissipation-based thermal resistance analysis of heat exchanger networks
}

\author{
QIAN XiaoDong, LI Zhen \& LI ZhiXin* \\ Key Laboratory of Thermal Science and Power Engineering of Ministry of Education, School of Aerospace, Tsinghua University, Beijing 100084, \\ China
}

Received April 25, 2011; accepted June 9, 2011

\begin{abstract}
Heat exchanger network optimization has an important role in high-efficiency energy utilization and energy conservation. The thermal resistance of a heat exchanger network is defined based on its entransy dissipation. In two-stream heat exchanger networks, only heat exchanges between hot and cold fluids are considered. Thermal resistance analysis indicates that the maximum heat transfer rate between two fluids corresponds to the minimum entransy-dissipation-based thermal resistance; i.e. the minimum thermal resistance principle can be exploited in optimizing heat exchanger networks.
\end{abstract}

heat exchanger network, entransy-dissipation-based thermal resistance, optimization, minimum thermal resistance principle

Citation: Qian X D, Li Z, Li Z X. Entransy-dissipation-based thermal resistance analysis of heat exchanger networks. Chinese Sci Bull, 2011, 56: 3289-3295, doi: $10.1007 / \mathrm{s} 11434-011-4733-3$

Heat exchanger networks (HENs) are widely used in energy transport and utilization. Two-stream HENs are a type of HENs in which hot and cold fluids do not exchange thermal energy directly through one heat exchanger due to environmental constraints or practical demands. Two-stream HENs usually consist of heat exchangers, distributors, mixers, and medial fluids. Two-stream HENs, regarded as an element of a large-scale HEN or an independent network, are widely used in heating, ventilation, air conditioning, industrial heat recovery and other fields, such as the solar heat network [1], thermochemical heat storage system [2], ground source heat pump system [3], and loop units in power plants [4]. The optimization of HEN is of great significance in high-efficiency energy utilization and energy conservation.

The initial study on HEN optimization was presented by Hwa [5] in 1965. With more than 40 years of development, two main methods, called the pinch design method and mathematical programming method, have been developed and are always used in HEN optimization. Hohmann [6] believed that thermodynamics needed to be considered in

*Corresponding author (email: lizhx@ @tsinghua.edu.cn)
HEN's optimization. Linnhoff [7] invented the pinch design method based on thermodynamic theory. Colbert [8] and Trivedi et al. [9] improved on this approach and introduced the dual temperature and pseudo-pinch method in HEN optimization. Analyzing by a mathematical programming method, a HEN is described by an objective function and constraint conditions. Cerda et al. [10] and Floudas et al. [11] solved this HEN optimization problem using linear programming (LP) and mixed-integer nonlinear programming (MINLP) methods respectively.

In optimization designs of two-stream HENs, the heat transfer rate is mainly of concern to designers. To maximize the heat recovery or heat transfer rate, much research has been performed. In the research of run-around heat recovery system, Fan et al. [12] found that the system had the highest efficiency when the heat capacity ratio of air and the medial fluid was in the range 0.8-1.2. Zhou et al. [13] found that a ground-coupled liquid loop heat recovery ventilation system had an optimal allocation ratio between heat exchangers and an optimal brine flow rate that provided maximum heat recovery efficiency. These authors found the optimum working condition for the networks but did not explain the phys- 
ical mechanism nor present a criterion for two-stream HEN optimization.

In the optimization analyses of heat exchangers, Bejan [14] used the minimum entropy generation principle and introduced the entropy generation number as the optimization criterion. However, a paradox appears while analyzing the counter-flow heat exchangers.

Guo et al. [15] introduced a new physical quantity, entransy, which represents the heat transfer ability of an object in heat transfer process. It is defined as

$$
G=Q_{h} T / 2
$$

where $Q_{h}$ is the internal thermal energy stored in an object with $T$ is its absolute temperature. During irreversible heat transfer, thermal energy is conserved, but entransy will be partially dissipated. The entransy balance equation is obtained by multiplying the heat conduction equation by $T$ :

$$
\rho c_{v} T \frac{\partial T}{\partial t}=-\nabla \cdot(q T)+q \cdot \nabla T \text {. }
$$

The left-hand side of eq. (2) represents the entransy variation with time, the first term on the right-hand side is the entransy flux, and the last term is the entransy dissipation due to heat conduction. The last term can be written as the entransy dissipation rate per unit volume:

$$
g_{\phi}=-q \cdot \nabla T=k(\nabla T)^{2} .
$$

Zhu [16] defined the thermal resistance based on entransy dissipation as

$$
R_{\phi}=\frac{G_{\phi}}{Q^{2}}
$$

where $R_{\phi}$ is the thermal resistance based on entransy dissipation, $G_{\phi}$ is the entransy dissipation during the heat transfer process, and $Q$ is the heat transfer rate. With the concept of entransy dissipation or thermal resistance based on entransy dissipation, researchers have conducted many optimization studies of heat conduction, heat convection and mass convection [17-23]. Chen and co-authors [21-23] combined the extremum entransy dissipation principle with the constructal theory and optimized many heat transfer systems based on entransy dissipation rate minimization. In researches of heat exchangers and HENs, Song et al. [24] demonstrated the uniformity principle of temperature difference field for one-dimensional heat exchanger based on the extremum entransy dissipation principle. Guo et al. $[25,26]$ defined the entransy dissipation number of heat exchangers, and introduced the principle of entransy dissipation equi-partition for heat exchanger design. Liu et al. [27,28] introduced the entransy-dissipation-based thermal resistance for a heat exchanger, and presented the minimum thermal resistance principle for heat exchanger optimization. Chen et al. [29] compared the applicability of the entropy generation mini- mization method with that of the entransy dissipation maximization method in two categories of heat exchangers groups. With the extremum entransy dissipation principle, Cheng et al. [30] optimized the parallel thermal network of a thermal control system designed for spacecraft.

Entransy analysis for a heat exchanger shows that minimum thermal resistances defined based on entransy dissipation always correspond to maximum heat transfer rates [31]. In this paper, the entransy-dissipation-based thermal resistance of two-stream HEN is defined and the thermal resistance analyses on two-stream HENs are performed to find the relation of thermal resistance and heat transfer rate.

\section{Thermal resistance of a two-stream HEN}

\subsection{Thermal resistance of a heat exchanger}

Liu et al. [27,28] formulated the entransy dissipation of heat exchanger and defined the thermal resistance based on entransy dissipation. The entransy dissipation of a heat exchanger is

$$
G_{\phi, \mathrm{ex}}=\left(\frac{1}{2} C_{h} T_{h, \mathrm{i}}{ }^{2}+\frac{1}{2} C_{c} T_{c, \mathrm{i}}{ }^{2}\right)-\left(\frac{1}{2} C_{h} T_{h, \mathrm{o}}{ }^{2}+\frac{1}{2} C_{c} T_{c, \mathrm{o}}{ }^{2}\right) .
$$

The entransy dissipation of the two fluids in heat exchanger equals the difference between total entransy rates entering into and leaving out the heat exchanger. Similar to eq. (4), the entransy-dissipation-based thermal resistance $R_{\phi, \text { ex }}$ of the heat exchanger is defined as

$$
R_{\phi, \mathrm{ex}}=\frac{G_{\phi, \mathrm{ex}}}{Q^{2}},
$$

where the subscript 'ex' signifies that the associated quantity refers to the heat exchanger, and $Q$ is the heat transfer rate between two fluids.

\subsection{Thermal resistance of a two-stream HEN with me- dial fluid}

Figure 1 depicts a schematic diagram of a two-stream HEN consisting of two counter-flow heat exchangers. The hot and cold fluids do not exchange thermal energy directly. A medial fluid bridges the two heat exchangers and exchanges thermal energy with the hot and cold fluids.

The heat transfer rates of the two heat exchangers are the same, if the heat loss from both exchangers and pipes are ignored. The medial fluid does not loose or gain thermal energy during heat transfer, that is, the net heat flow is zero. The entransy-dissipation-based thermal resistance of the two-stream HEN is then defined as

$$
R_{\phi}=\frac{G_{\phi 1}+G_{\phi 2}}{Q^{2}}
$$

where the heat exchangers are labeled 1 and 2, the entransy 


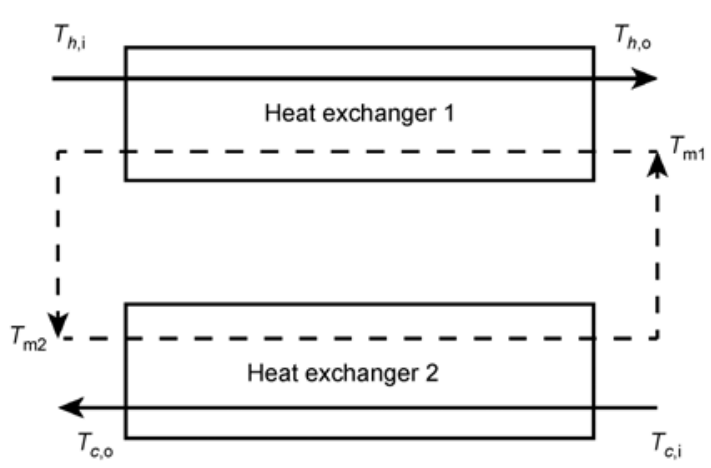

Figure 1 Two-stream HEN with a medial fluid.

dissipations of each can be calculated by eq. (5), and $Q$ is the heat transfer rate between hot and cold fluids equaling the heat transfer rate of heat exchanger 1 or 2 .

\subsection{Thermal resistance of a two-stream HEN with mixers}

Figure 2 shows a diagram of a two-stream HEN with mixers, the network comprising two counterflow heat exchangers, two mixers, and two distributors. Two distributors, one each for the hot and cold fluids, divide and direct counter-moving flows into the two heat exchangers to enable an exchange of thermal energy, before finally, flowing through the two mixers. Entransy dissipation occurs during heat transfer in the two exchangers and in mixing in the two mixers.

The corresponding thermal resistance $R_{\phi}$ for the twostream HEN with mixers can be defined as

$$
R_{\phi}=\frac{G_{\phi 1}+G_{\phi 2}+G_{\phi h, \text { mix }}+G_{\phi c, \text { mix }}}{\left(Q_{1}+Q_{2}\right)^{2}}
$$

where $G_{\phi h \text {,mix }}$ and $G_{\phi c \text {,mix }}$ are the respective entransy dissipations in mixing of two hot fluids and two cold fluids, $Q_{1}$ and

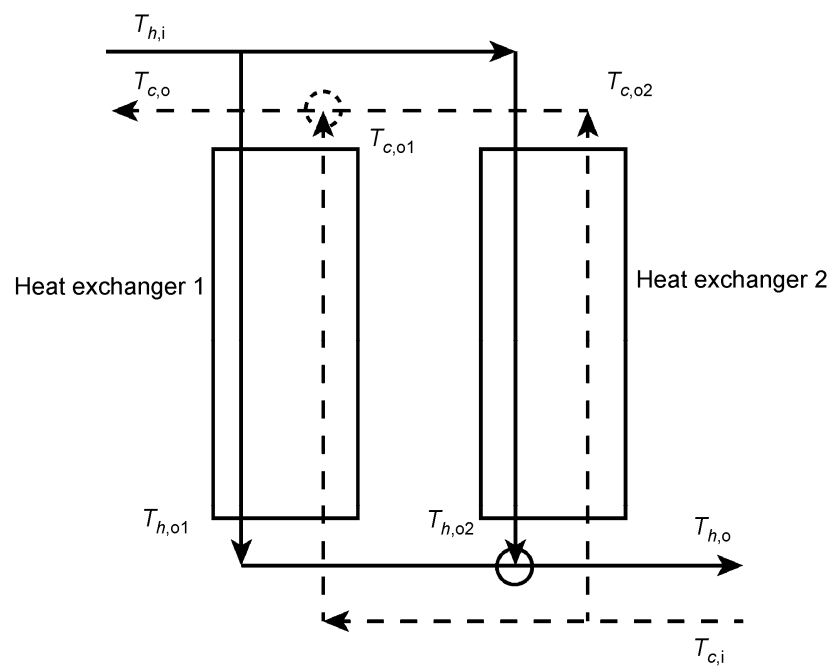

Figure 2 Two-stream HEN with mixers.
$Q_{2}$ are the heat transfer rates of the two heat exchangers.

\subsection{Thermal resistance of a two-stream HEN}

The above represents the basic elements which can be generalized to a two-stream HEN with many heat exchangers. Suppose there are $k$ heat exchangers, $r$ mixers, and some distributors, the total entransy dissipation now equals the sum of the entransy dissipations during heat transfer in each heat exchanger and during mixing within each mixer. That is,

$$
G_{\phi, \mathrm{HEN}}=\sum_{k} G_{\phi, \mathrm{ex}}+\sum_{r} G_{\phi, \mathrm{mix}},
$$

where $G_{\phi, \mathrm{HEN}}$ is the total entransy dissipation for a twostream HEN, $G_{\phi, \text { ex }}$ and $G_{\phi, \text { mix }}$ are the respective entransy dissipations in each heat exchanger and mixer. The entransy dissipation during separation equals zero, because the separating process is isothermally performed. The heat transfer rate of HEN equals the thermal energy decrement of the hot fluid or the equivalent thermal energy increment of the cold fluid. Next, we define the entransy-dissipation-based thermal resistance of the two-stream HEN as

$$
R_{\phi, \mathrm{HEN}}=\frac{G_{\phi, \mathrm{HEN}}}{Q_{\mathrm{HEN}}^{2}},
$$

where the subscript HEN relates quantities to the heat exchanger network.

\section{Thermal resistance analyses}

\subsection{Analysis of a two-stream HEN with a medial fluid}

There are two kinds of optimizations for the two-stream HEN with medial fluid. If the ratio of the hot to cold fluid heat capacity rates is given along with the thermal conductances (overall heat transfer coefficient times heat transfer surface area) of the two heat exchangers, a two-stream HEN with medial fluid can be optimized by changing the heat capacity rate of the medial fluid, that amounts to optimizing the heat capacity rate ratio of the two heat exchangers. Alternatively, if the heat capacity rates of the hot fluid, cold fluid, and the medial fluid are given as well as the total thermal conductance of the two heat exchangers, the optimization of a HEN can be performed by changing the thermal conductance ratio of the two heat exchangers. The parameters prescribing the two-stream HEN with medial fluid, shown in Figure 1, are listed in Table 1.

From the optimization of a two-stream HEN, numerical results for the heat transfer rate and the entransy-dissipationbased thermal resistance versus the heat capacity rate of medial fluid are plotted in Figure 3, where the heat capacity rate ratio of the hot-to-cold fluid and thermal conductances of the two heat exchangers are given. Under the given 
Table 1 Parameters of a two-stream HEN with a medial fluid

\begin{tabular}{|c|c|c|c|c|c|}
\hline \multicolumn{2}{|c|}{ Hot fluid } & \multicolumn{2}{|c|}{ Cold fluid } & Heat exchanger 1 & Heat exchanger 2 \\
\hline Inlet temperature & Heat capacity rate 1 & Inlet temperature & Heat capacity rate & \multicolumn{2}{|c|}{ Thermal conductance } \\
\hline $500 \mathrm{~K}$ & $400 \mathrm{~W} / \mathrm{K}$ & $300 \mathrm{~K}$ & $200 \mathrm{~W} / \mathrm{K}$ & $1000 \mathrm{~W} / \mathrm{K}$ & $2000 \mathrm{~W} / \mathrm{K}$ \\
\hline
\end{tabular}

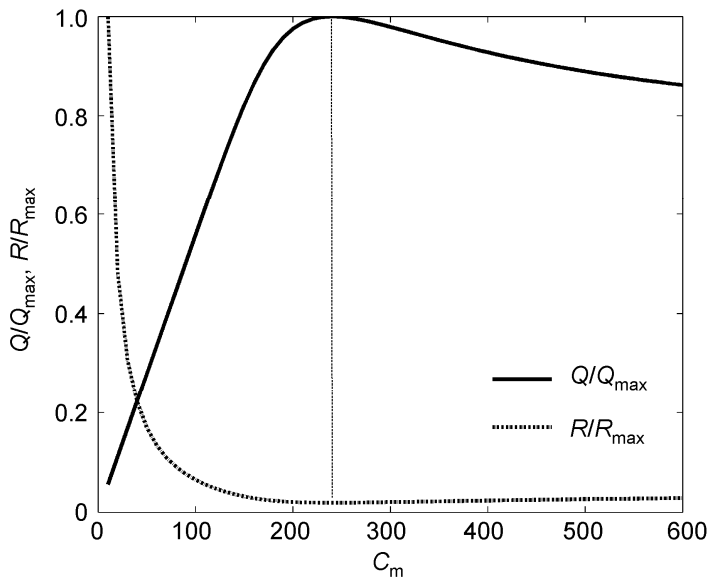

Figure 3 Heat transfer rate and thermal resistance versus the heat capacity rate of medial fluid.

parameters, it is seen that the heat transfer rate first increases, then decreases as the heat capacity rate of the medial fluid increases. A maximum heat transfer rate between hot and cold fluids exists. In contrast, the entransy-dissipationbased thermal resistance first decreases, and then slowly increases. Here, the minimum thermal resistance corresponds to a maximum heat transfer rate. The optimal heat capacity rate of medial fluid reads off from Figure 3 is 240 $\mathrm{W} / \mathrm{K}$ where the heat transfer rate is maximal.

Similarly, numerical results for the same quantities as in Figure 3 are given in Figure 4 against the ratio of thermal conductance of heat exchanger 1 to the total thermal conductance. The heat capacity rate of the medial fluid is 200 $\mathrm{W} / \mathrm{K}$ and the sum of the thermal conductances for the two heat exchangers is $3000 \mathrm{~W} / \mathrm{K}$. It is seen that the heat transfer rate between hot and cold fluids exhibits a peak; again, a maximum heat transfer rate exists. Also as before, the minimum entransy-dissipation-based thermal resistance is corresponding to the maximum heat transfer rate. The optimal thermal conductance ratio is 0.41 and is related to the ratio of the heat transfer surface area of heat exchanger 1 to the total heat transfer surface area of the two heat exchangers if their overall heat transfer coefficients are fixed.

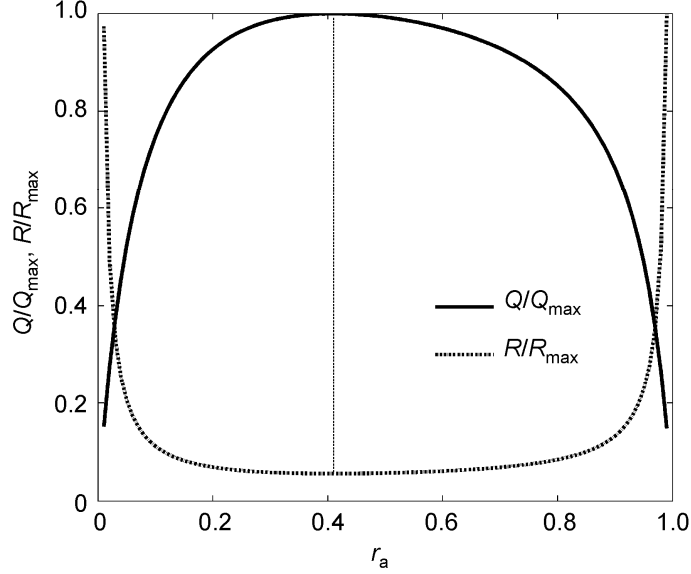

Figure 4 Heat transfer rate and thermal resistance versus the thermal conductance ratio.

\subsection{Analysis of a two-stream HEN with mixers}

A similar analysis to the above is performed for a twostream HEN with mixers, shown schematically in Figure 2. The parameters for this type of HEN are listed in Table 2.

In the numerical analysis, the heat capacity rates of the hot fluid in the two heat exchangers and the total heat capacity rate of the cold fluid are held fixed, the thermal conductances of heat exchangers 1 and 2 are $1000 \mathrm{~W} / \mathrm{K}$ and $2000 \mathrm{~W} / \mathrm{K}$, respectively. In Figure 5, the heat transfer rate between hot and cold fluids and the entransy-dissipationbased thermal resistance of the HEN are plotted against $r_{\mathrm{c}}$, the ratio of cold heat capacity rate in heat exchangers 1 to the total cold fluid heat capacity rate. It is seen that there exists a maximum in the heat transfer rate and a minimum in the entransy-dissipation-based thermal resistance. If the heat capacity rate of cold fluid in heat exchanger 1 is 284 $\mathrm{W} / \mathrm{K}$, i.e., $r_{\mathrm{c}}=0.71$, the heat transfer rate attains its maximum value, concurrent with a minimum in the thermal resistance.

If the heat capacity rates of the hot fluid in heat exchangers 1 and 2 are $200 \mathrm{~W} / \mathrm{K}$ and $100 \mathrm{~W} / \mathrm{K}$, the heat capacity rates of cold fluid in heat exchangers 1 and 2 are both 200 $\mathrm{W} / \mathrm{K}$, and the total thermal conductance of the two heat exchangers is $3000 \mathrm{~W} / \mathrm{K}$, the two-stream HEN with mixers

Table 2 Parameters of a two-stream HEN with mixers

\begin{tabular}{|c|c|c|c|c|c|c|}
\hline \multicolumn{3}{|c|}{ Hot fluid } & \multicolumn{2}{|c|}{ Cold fluid } & Heat exchanger 1 & Heat exchanger 2 \\
\hline Inlet temperature & Heat capacity rate 1 & Heat capacity rate 2 & Inlet temperature & Heat capacity rate & \multicolumn{2}{|c|}{ Thermal conductance } \\
\hline $500 \mathrm{~K}$ & $200 \mathrm{~W} / \mathrm{K}$ & $100 \mathrm{~W} / \mathrm{K}$ & $300 \mathrm{~K}$ & $400 \mathrm{~W} / \mathrm{K}$ & $1000 \mathrm{~W} / \mathrm{K}$ & $2000 \mathrm{~W} / \mathrm{K}$ \\
\hline
\end{tabular}




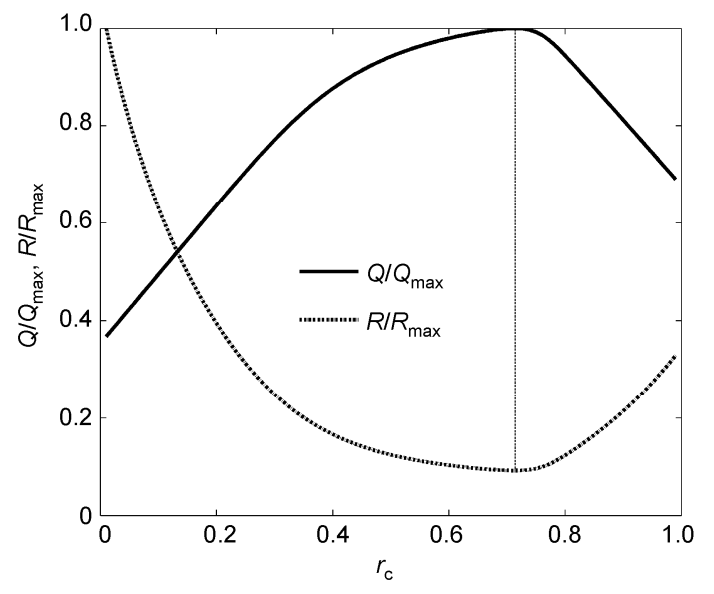

Figure 5 Heat transfer rate and thermal resistance versus cold heat capacity rate ratio.

can be optimized by changing the ratio of thermal conductance 1 to the total thermal conductance, $r_{\mathrm{a}}$ The analogous numerical results, plotted in Figure 6 , again produce a maximum heat transfer rate between hot and cold fluids and a minimum entransy-dissipation-based thermal resistance. These extrema occur when the thermal conductance ratio $r_{\mathrm{a}}$, equals 0.75 .

\subsection{Analysis of a two-stream HEN with medial fluid and mixers}

Combining the two types of two-stream HEN discussed above, we construct a simple two-stream HEN with both

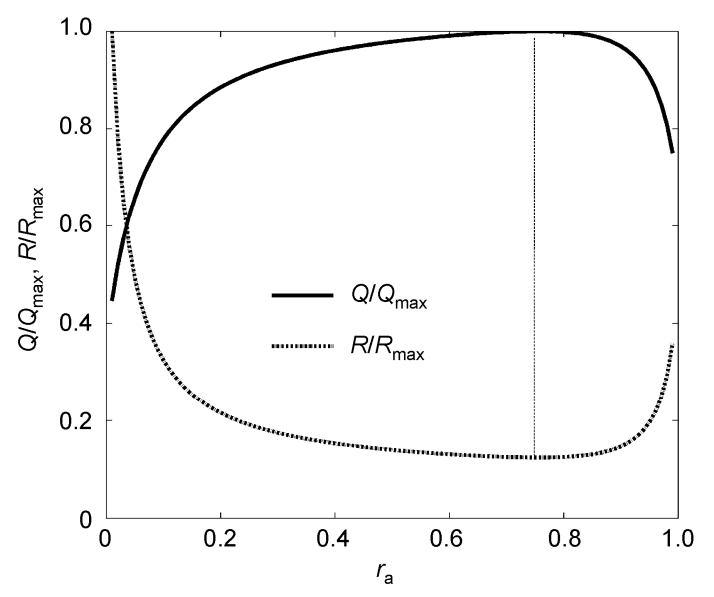

Figure 6 Heat transfer rate and thermal resistance versus the thermal conductance ratio. medial fluid and mixers, schematically shown in Figure 7. In this HEN, there are three counterflow heat exchangers, one hot fluid, one cold fluid, one medial fluid and two mixers, the parameters are listed in Table 3.

Its optimal working conditions can be obtained by optimizing $c_{\mathrm{m}}$, the total heat capacity rate of the medial fluid, and $r$, the ratio of medial fluid heat capacity rate in heat exchanger 1 to the total medial fluid heat capacity rate. In numerical simulations, the total heat capacity rate of the medial fluid was varied from 500 to $2500 \mathrm{~W} / \mathrm{K}$, and the ratio of the medial fluid heat capacity rate varied from 0 to 1 . The normalized heat transfer rate between hot and cold fluids and the entransy-dissipation-based thermal resistance are presented in Figure 8, where the convex surface corresponds to the heat transfer rate, the concave surface displays

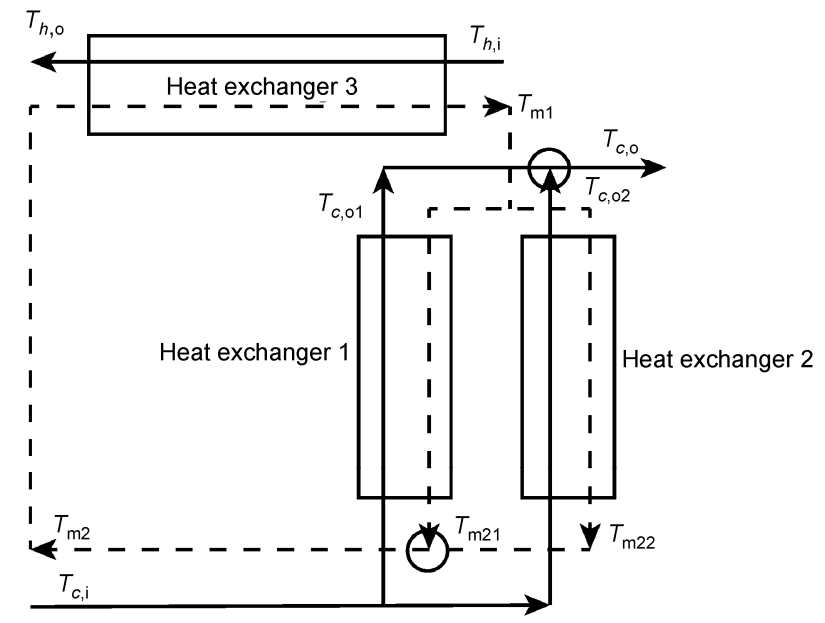

Figure 7 Two-stream HEN with both medial fluid and mixers.

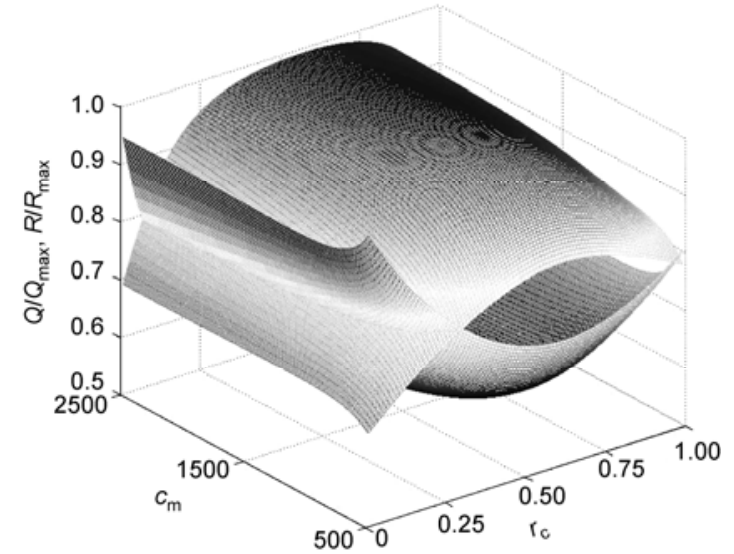

Figure 8 Numerical results for the heat transfer rate and entransy-dissipation-based thermal resistance of the HEN described in Figure 7 and Table 3.

Table 3 Parameters of the two-stream HEN with both medial fluid and mixers

\begin{tabular}{|c|c|c|c|c|c|c|}
\hline \multicolumn{2}{|c|}{ Hot fluid } & \multicolumn{2}{|r|}{ Cold fluid } & Heat exchanger 1 & Heat exchanger 2 & Heat exchanger 3 \\
\hline Inlet temperature & Heat capacity rate & Inlet temperature & Heat capacity rate 1 Heat capacity rate 2 & & Thermal conductan & \\
\hline $500 \mathrm{~K}$ & $1000 \mathrm{~W} / \mathrm{K}$ & $300 \mathrm{~K}$ & $1000 \mathrm{~W} / \mathrm{K}$ & $800 \mathrm{~W} / \mathrm{K}$ & $1500 \mathrm{~W} / \mathrm{K}$ & $1000 \mathrm{~W} / \mathrm{K}$ \\
\hline
\end{tabular}


the entransy-dissipation-based thermal resistance of the HEN.

The numerical results indicate that the heat transfer rate between hot and cold fluids and the entransy-dissipationbased thermal resistance attain extrema when $c_{\mathrm{m}}$ is 1490 $\mathrm{W} / \mathrm{K}$ and $r$ is 0.59 . To understand the influences of $c_{\mathrm{m}}$ and $r$, the heat transfer rate between hot and cold fluids and the entransy-dissipation-based thermal resistance can be calculated for different $r$ when $c_{\mathrm{m}}$ is optimally fixed, and for different $c_{\mathrm{m}}$, when $r$ is optimally fixed, the two sets of results are plotted in Figures 9 and 10, respectively. Once again, the maximum heat transfer rate between hot and cold fluids corresponds to the minimum entransy-dissipation-based thermal resistance. According to these numerical results, we conclude that the minimum thermal resistance principle holds in the optimization of two-stream HENs. This can be stated as follows: under the same conditions, the lower the entransy-dissipation-based thermal resistance is, the higher the heat transfer rate between hot and cold fluids in the two-stream HEN will be.

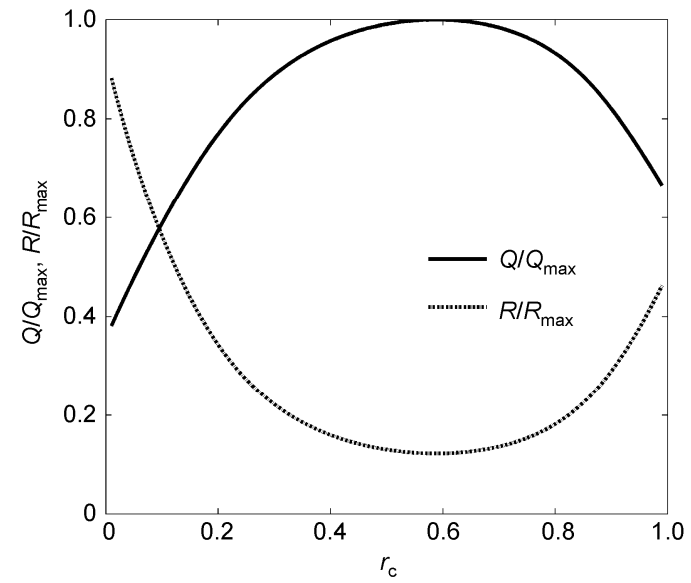

Figure 9 Heat transfer rate and entransy-dissipation-based thermal resistance versus $r\left(c_{\mathrm{m}}=1490 \mathrm{~W} / \mathrm{K}\right)$.

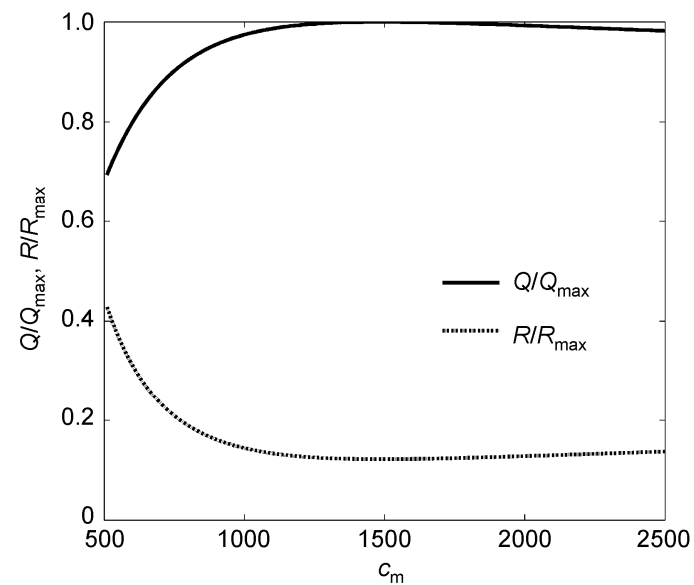

Figure 10 Heat transfer rate and entransy-dissipation-based thermal resistance versus $c_{\mathrm{m}}(r=0.59)$.

\section{Conclusion}

Similar to the definition of the entransy-dissipation-based thermal resistance of a heat exchanger, the entransy-dissipation-based thermal resistance of a two-stream HEN was defined, where the entransy dissipation during mixing was taken into consideration. Numerical analyses for three simple two-stream HENs indicate that the maximum heat transfer rates between hot and cold fluids always corresponded to the minimum entransy-dissipation-based thermal resistance. The two-stream HEN can be optimized using the minimum thermal resistance principle, which states: under the same conditions, the lower the entransy-dissipationbased thermal resistance is, the higher the heat transfer rate between hot and cold fluids in the two-stream HEN will be.

Further work will focus on the thermal resistance analysis of more complicated heat transfer networks, involving multiple streams.

This work was supported by the National Basic Research Program of China (G2007CB206901).

1 Weiss W. Solar Heating Systems for Houses: A Design Handbook for Solar Combi-systems. London: Earthscan Publications Ltd., 2004

2 Hauer A. Adsorption system for TES-design and demonstration projects. Therm Energy Stor Sust Energy Cons, 2007, 234: 409-427

3 Omer A M. Ground-source heat pumps systems and applications. Renew Sust Energy Rev, 2008, 12: 344-371

4 Shultis J K, Faw R E. Fundamentals of Nuclear Science and Engineering. New York: Marcel Dekker, 2002

5 Hwa C S. Mathematical Formulation and Optimization of Heat Exchanger Networks Using Separable Programming. AIChE-IChemE Symposium Series 4. New York: AIChE, 1965. 101-106

6 Hohmann E C. Optimum Networks for Heat Exchanger. Los Angeles: University of Southern California, 1971

7 Linnhoff B, Hindmarsh E. The pinch design method for heat exchanger networks. Chem Eng Sci, 1983, 38: 745-763

8 Colbert R W. Industrial heat exchanger networks. Chem Eng Prog, 1982, 78: 47-54

9 Trivedi K K, O’Neill B K, Roach J R. A new dual-temperature design method for the synthesis of heat exchanger networks. Comput Chem Eng, 1989, 13: 667-685

10 Cerda J, Westerberg A W, Mason D, et al. Minimum utility usage in heat exchanger network synthesis. Chem Eng Sci, 1983, 38: 373-387

11 Flousas C A, Ciric A R, Grossmann I E. Automatic synthesis of optimum heat exchanger network configurations. AIChE J, 1986, 32: 276-290

12 Fan H, Simonson C J, Besant R W. Run-around heat recovery system using cross-flow flat-plate heat exchangers with aqueous ethylene glycol as the coupling fluid. ASHRAE Trans, 2005, 111: 901-910

13 Zhou Y S, Fahlen P, Lindholm T. Performance and optimization for a ground-couple liquid loop heat recovery ventilation system (in Chinese). J Donghua Univ, 2007, 24: 749-755

14 Bejan A. Concept of irreversibility in heat exchanger design: Counter-flow heat exchangers for gas-to-gas applications. J Heat Transfer, 1977, 99: 374-380

15 Guo Z Y, Zhu H Y, Liang X G. Entransy-a physical quantity describing heat transfer ability. Int J Heat Mass Transfer, 2007, 52: 2545-2556

16 Zhu H Y. The minimum thermal resistance principle based on entransy dissipation. Ph.D. Thesis. Beijing: Tsinghua University, 2007 
17 Chen Q, Ren J X, Guo Z Y. The extremum principle of mass entransy dissipation and its application to decontamination ventilation designs in space station cabins. Chinese Sci Bull, 2009, 54: 2862-2870

18 Wang S P, Chen Q L, Zhang B J. An equation of entransy transfer and its application. Chinese Sci Bull, 2009, 54: 3572-3578

19 Chen L, Chen Q, Li Z, et al. Moisture transfer resistance method for liquid desiccant dehumidification analysis and optimization. Chinese Sci Bull, 2010, 55: 1445-1453

20 Song W M, Meng J A, Li Z X. Optimization of flue gas convective heat transfer with condensation in a rectangular channel. Chinese Sci Bull, 2011, 56: 263-268

21 Xie Z H, Chen L G, Sun F R. Constructal optimization on T-shaped cavity based on entransy dissipation minimization. Chinese Sci Bull, 2009, 54: 4418-4427

22 Wei S H, Chen L G, Sun F R. Constructal optimization of discrete and continuous-variable cross-section conducting path based on entransy dissipation rate minimization. Sci China Tech Sci, 2010, 53: 1666-1677

23 Xiao Q H, Chen L G, Sun F R. Constructal entransy dissipation rate and flow-resistance minimizations for cooling channels. Sci China Tech Sci, 2010, 53: 2458-2468

24 Song W M, Meng J A, Liang X G, et al. Demonstration of uniformity principle of temperature difference field for one-dimensional heat exchangers. J Chem Ind Eng, 2008, 59: 2460-2464

25 Guo J F, Cheng L, Xu M T. Entransy dissipation number and its application to heat exchanger performance evaluation. Chinese Sci Bull, 2009, 54: 2708-2713

26 Guo J F, Xu M T, Cheng L. Principle of equipartition of entransy dissipation for heat exchanger design. Sci China Tech Sci, 2010, 53: 1309-1314

27 Liu X B, Meng J A, Guo Z Y. The analysis of thermal resistance of heat exchange based on entransy dissipation. Prog Nat Sci, 2008, 18: 146-152

28 Liu X B, Meng J A, Guo Z Y. The external entropy production and entransy dissipation in parameter optimization of heat exchangers. Chinese Sci Bull, 2008, 53: 3026-3029

29 Chen Q, Wu J, Wang M R, et al. A comparison of optimization theories for energy conservation in heat exchanger groups. Chinese Sci Bull, 2011, 56: 449-454

30 Cheng X T, Xu X H, Liang X G. Application of entransy to optimization design of parallel thermal network of thermal control system in spacecraft. Sci China Tech Sci, 2011, 54: 964-971

31 Qian X D, Li Z X. Analysis of entransy dissipation in heat exchangers. Int J Therm Sci, 2011, 50: 608-614

Open Access This article is distributed under the terms of the Creative Commons Attribution License which permits any use, distribution, and reproduction in any medium, provided the original author(s) and source are credited. 